\title{
ROBOT PENJEJAK RUANGAN DENGAN SENSOR ULTRASONIK DAN KENDALI GANDA MELALUI BLUETOOTH
}

\author{
Fathur Zaini Rachman ${ }^{1 *}$, Nur Yanti ${ }^{2}$ \\ ${ }^{1,2}$ Teknik Elektronika, Politeknik Negeri Balikpapan \\ *e-mail : fozer85@gmail.com
}

\begin{abstract}
This research aimed for planning and implementation mobile robot with control in an automatic and manual that used sensor ultrasonic as a detection object and also used Bluetooth technology as a control in a manual mobile robot via smartphone. This mobile robot can detect obstacle around it and have a navigation system. If ultrasonic sensor detect an obstacle, then mobile robot will turn and running in a automatic without hit or object around it. This mobile robot can do communication bi-directional, sensoring process, and recognize ID or character from controller. This mobile robot application consists of circuit controller and mobile robot circuit controller consists of smartphone and Bluetooth application. Mobile robot consists of arduino mega 2560 , driver module, sensor ultrasonic, and Bluetooth HC-05 module.
\end{abstract}

Keyword: Mobile Robot, Sensor Ultrasonic, Bluetooth Technolgy

\begin{abstract}
Abstrak
Penelitian ini bertujuan untuk melakukakan perencanaan dan implementasi mobile robot dengan kontrol secara otomatis dan manual yaitu menggunakan sensor ultrasonic sebagai pendeteksi objek dan juga menggunakan teknologi Bluetooth sebagai pengendalian manual mobile robot via smartphone . Mobile robot ini mampu mendeteksi penghalang yang ada disekitarnya dan memiliki sistem navigasi. Jika sensor ultrasonik mendeteksi adanya penghalang, maka robot akan berbelok dan berjalan secara otomatis tanpa menabrak penghalang ataupun benda yang berada disekitarnya. Mobile robot ini mampu melakukan komunikasi bidirectional, proses sensoring, dan mengenali ID ataupun karakter dari controller. Aplikasi mobile robot ini terdiri dari rangkaian controller dan mobile robot. Rangkaian controller terdiri dari smartphone dan aplikasi Bluetooth. Rangkaian mobile robot terdiri dari Arduino mega 2560 ,modul driver, sensor ultrasonic, dan modul Bluetooth HC-05.
\end{abstract}

Kata Kunci : Mobile Robot, Sensor Ultrasonic, Teknologi Bluetooth

\section{Pendahuluan}

Teknologi adalah cara untuk mendapatkan sesuatu dengan kualitas lebih baik (lebih mudah, lebih murah, lebih cepat, dan lebih menyenangkan). Salah satu teknologi yang berkembang pesat saat ini adalah teknologi di bidang robotika. Robotika tidak lagi dipandang sebagai ilmu yang berkembang hanya dalam konteks teknologi yang berupa fisik saja , namun semakin hari semakin banyak masalah yang berkaitan dengan lingkungan hidup manusia yang perlu diperhatikan.

Sensor ultrasonik dalam robot sebagai pengukur jarak untuk memberikan masukan kapan robot harus maju atau harus berbelok, sistem kerja sensor ultrasonik yaitu dengan memancarkan gelombang suara dan memantulkannya jika mengenai objek yang ada didepannya [1].

Saat ini teknologi komunikasi Bluetooth kebanyakan hanya digunakan sebagai sarana transfer data dan masih sangat jarang digunakan sebagai pengendali suatu perangkat keras [2]. Mengingat perkembangan teknologi Bluetooth dan sensor ultrasonik yang semakin pesat tetapi ruang lingkup aplikasiannya yang masih sangat kecil, maka direncanakan sebuah mobile robot penjajak ruang yang dikontrol oleh aplikasi smartphone dengan 
menggunakan teknologi bluetooth dan sistem navigasi otomatis menggunakan sensor ultrasonik yang berjalan mendeteksi penghalang (wall) yang ada disekitarnya.

\section{Metoda Penelitian}

Metoda penelitian ini dilakukan unuk merancang dan membuat aplikasi dari perancangan, pembuatan dan pengujian keseluruhan. Untuk mendapatkan hasil yang baik, diperlukan langkah- langkah yang tepat dan beruntun . Hal ini dimaksudkan utuk memberikan kemudahan bagi peneliti dalam merancang, membangun, dan menganalisa, dan perbaikan kesalahan alat. Adapun metoda penelitian seperti pada gambar 1 .

\subsection{Perancangan Sistem Robot}

Secara umum robot otomatis terdiri dari tiga bagian dasar, yaitu bagian perangkat keras (hardware), bagian perangkat lunak (software), dan bagian mekanik. Adapun perencanaan sistem kerja dari robot dengan menggunakan controller dalam penelitian ini dapat digambarkan secara blok diagram pada gambar 2 .

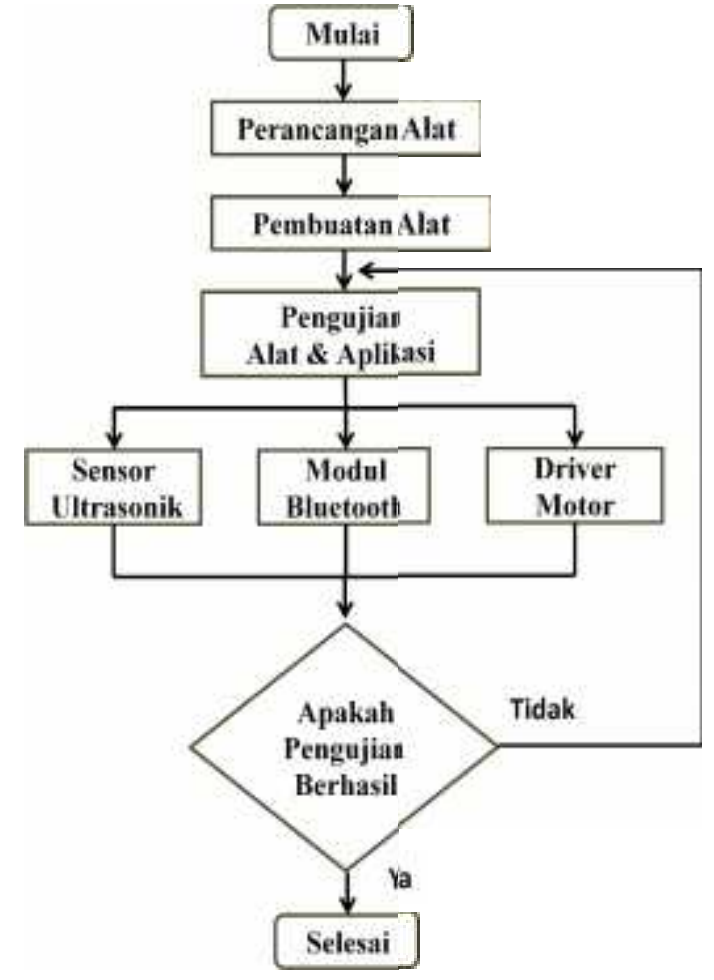

Gambar 1. Metoda Penelitian

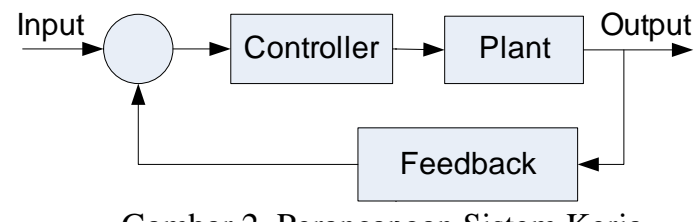

Gambar 2. Perancangan Sistem Kerja

\subsubsection{Blok Diagram Sistem}

Secara Lengkap blok diagram dari sistem dapat dilihat gambar 3 .

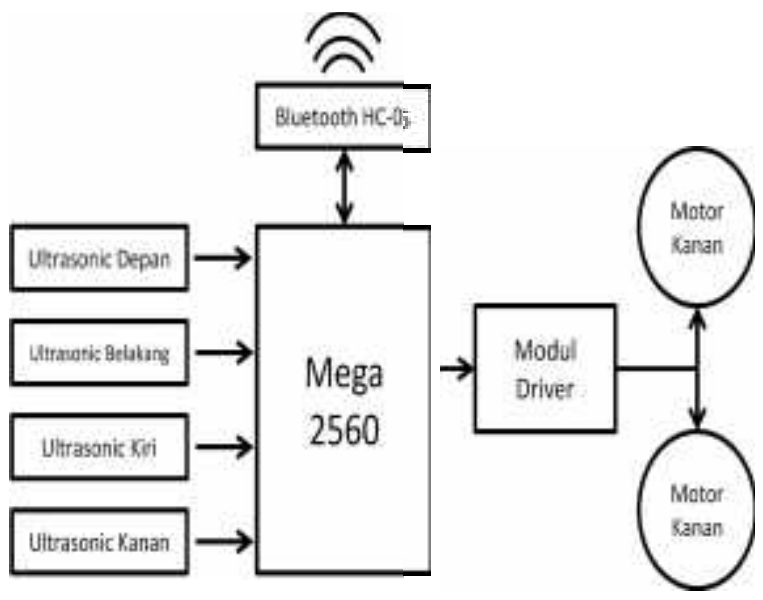

Gambar.3 Blok Diagram Sistem 


\subsubsection{Prinsip Kerja Robot}

Hal yang pertama dilakukakan adalah membuat sketch program untuk sistem mobilisasi robot dari mulai inialisasi dimana pada bagian ini terdapat deklarasi untuk sensor ultrasonik, Bluetooth, motor maupun variabel-variabel yang berhubungan penentuan tipe data apa yang digunakan. Selanjutnya adalah pengaturan konfigurasi pin input dan output Kemudian pemanggilan fungsi masing-masing sensor yang terlebih dahulu dibuat variabelnya yaitu ping 1-4 dan juga pemanggilan variable bluetooth. Lalu untuk memudahkan dalam penulisan dan pengecekan program maka dibuat konfigurasi untuk putaran motornya dengan memberikan nama variabel yaitu void maju(), void mundur(), void kiri(), dan void henti(). Kemudian dilakukan percabangan untuk beberapa pembacaan sensor dan kondisi yaitu pemanggilan karakter dari bluetooth dan kondisi pada saat sensor ultrasonik mendapatkan objek yang ada disekitarnya. Pada sistem kerja robot terjadi secara otomatis pada selang waktu tertentu sehingga pengguna dapat melihat hasil pembacaannya. Apabila robot bergerak maju dan pada proses sensoring jarak terdeteksi bahwa jarak antara robot dan penghalang terlalu dekat, maka secara otomatis robot akan berbelok. Jarak antar sensor dan objek yang memantulkan gelombang suara dihitung dengan menggunakan rumus [3][4]:

Jarak $=$ Kecepatan Suara $*$ T $/ 2$...(1)

Dalam hal ini $\mathrm{T}$ adalah waktu tempuh dari saat sinyal ultrasonik dipancarkan hingga kembali dan kecepatan suara adalah 343 meter / detik atau sama dengan 34300 $\mathrm{cm} /$ detik, sedangkan $\mathrm{T}$ yang dihasilkan oleh Arduino dalam satuan mikrodetik, maka $\mathrm{T}$ jika dinyatakan dalam satuan detik akan berupa $\mathrm{T} / 10^{-6}$. Oleh karena itu, jarak dalam satuan $\mathrm{cm}$ adalah:

$$
\begin{aligned}
\text { Jarak } & =34300 *\left(\mathrm{~T} / 10^{-6}\right) / 2 \mathrm{~cm} \\
& =0.0343 * \mathrm{~T} / 2 \mathrm{~cm} \ldots \ldots \ldots \ldots
\end{aligned}
$$

Seperti pada gambar 4, Sensor ultrasonic ping akan bekerja jika mendapat suplay tegangan sebesar $5 \mathrm{~V}$ DC. dimana tegangan $5 \mathrm{~V}$ DC dihubungkan dengan konektor Vcc dan ground pada sensor. Untuk konektor SIG dapat dihubungkan dengan mikrokontroler. Konektor SIG adalah sebagai kontrol sensor ini dalam pendeteksian objek sekaligus pembacaan jarak objek dengan sensor ini. progamer dapat mensetting sensor ini dengan jarak yang telah ditentukan sesuai dengan ring deteksi dari sensor ultrasoni ping ini sesuai dengan kebutuhan penggunaan dari sensor tersebut [5]. Ketika sensor disetting jaraknya maka dengan jarak yang telah ditentukanlah sensor akan bekerja dalam pendeteksian objek. Kisaran jarak yang dapat di baca sensor ultrasonic ping ini adalah $3 \mathrm{~cm}$ sampai $3 \mathrm{~m}$ [6]. Selain range jarak antara $3 \mathrm{~cm}$ sampai $3 \mathrm{~m}$ yang mampu dideteksi oleh sensor ultrasonik ping, sudut pancaran dari sensor jarak ultrasonic ping adalah dari $0^{\circ}$ sampai dengan $30^{\circ}$ [7].
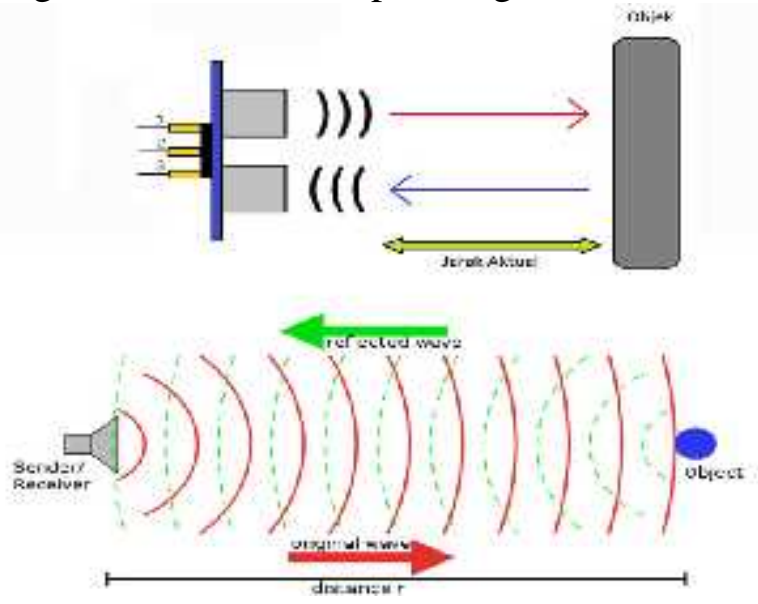

Gambar 4. Prinsip Kerja Sensor Ping 


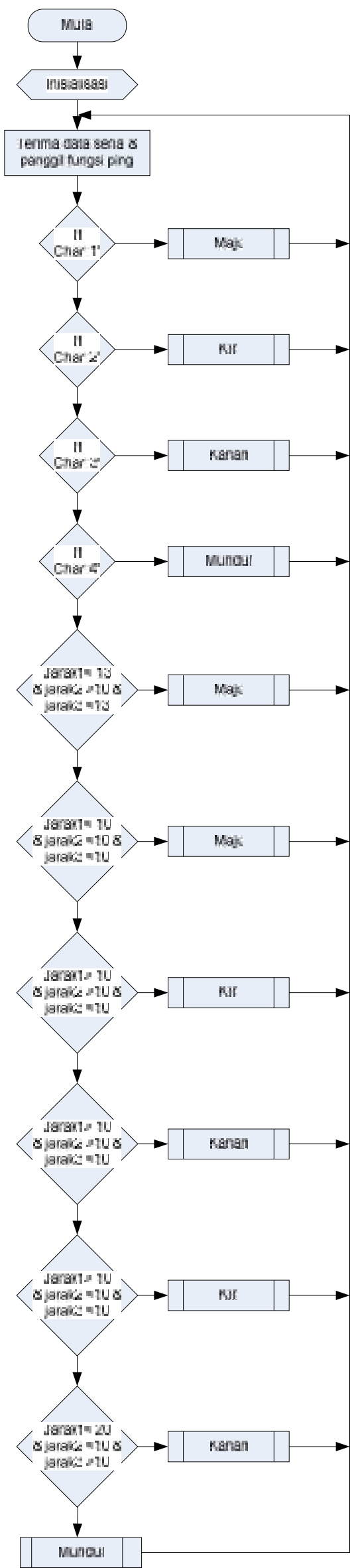

Gambar 5. Diagram alir program

\subsubsection{Perancangan Program Aplikasi}

Pada mikrokontroller arduino mega 2560 menggunakan software arduino IDE. Setelah program ditulis maka selanjutnya adalah upload ke dalam arduino mega 2560. Untuk aplikasi smartphone yang menghubungkan robot melalui koneksi bluetooth yaitu menggunakan bluetooth controller seperti gambar 6 dibawah ini.

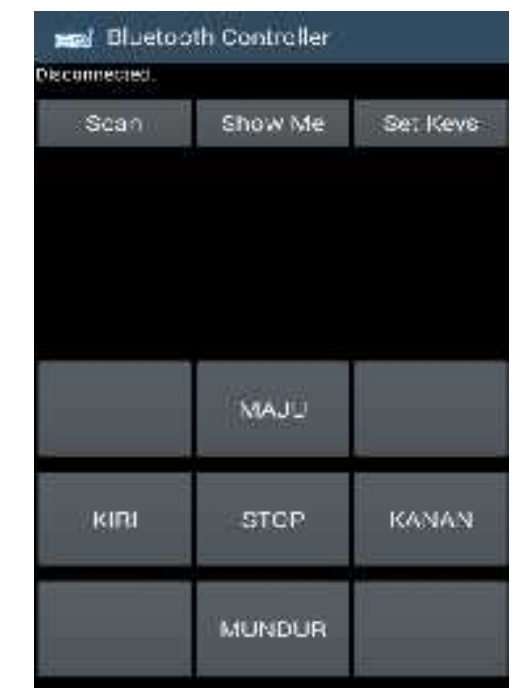

Gambar 6. Aplikasi Pada Smartphone

\subsubsection{Perancangan Robot}

Pada perancangan fisik robot terdiri dari input, proses dan output. Input terdiri dari sensor ultrasonik sebagai pendeteksi jarak ruang, proses menggunakan arduino sebagai pengolah data dari sensor dan output menggunakan driver motor untuk menggerakkan motor 12 volt. Bentuk fisik dari robot seperti pada gambar 7 .

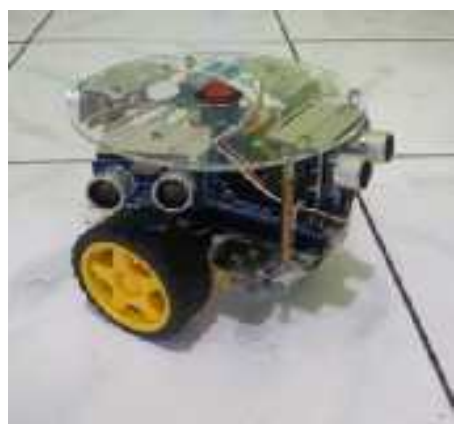

Gambar 7. Bentuk Fisik Robot

\section{Hasil Penelitian}

\subsection{Pengujian Keseluruhan Sistem}

Pada pengujian keseluruhan sistem yaitu menguji setiap komponen ataupun 
bagian- bagian yang digunakan pada robot untuk mengetahui kondisi bagian tersebut apakah berjalan sesuai dengan baik. Tujuan pengujian ini untuk mengetahui tanggapan robot apakah sesuai dengan apa yang di inginkan .

\section{Langkah Pengujian :}

1. Mengupload program terlebih dahulu

2. Mengaktifkan semua komponen robot.

3. Membuat sebuah jalur wall untuk pengujian ultrasonic

4. Hubungkan aplikasi yang ada pada smartphone ke modul bluetooth

5. Lakukan pengujian kondisi yang telah dibuat pada

\section{Hasil Pengujian :}

Pada hasil pengujian ini tujuannya untuk menganalisa kondisi berjalannya robot yang ada pada metoda teori dan praktek :

Tabel 1. Pengujian Tingkat Keakuratan Bleutooth

\begin{tabular}{|c|c|c|}
\hline $\begin{array}{l}\text { Jarak } \\
\text { Meter }\end{array}$ & $\begin{array}{l}\text { Kondisi } \\
\text { Ruangan }\end{array}$ & Keterangan \\
\hline \multirow[t]{2}{*}{4} & $\begin{array}{c}\text { Ada } \\
\text { Halangan }\end{array}$ & Mendeteksi \\
\hline & $\begin{array}{c}\text { Tanpa } \\
\text { Halangan } \\
\end{array}$ & Mendeteksi \\
\hline \multirow[t]{2}{*}{8} & $\begin{array}{c}\text { Ada } \\
\text { Halangan }\end{array}$ & Mendeteksi \\
\hline & $\begin{array}{c}\text { Tanpa } \\
\text { Halangan }\end{array}$ & Mendeteksi \\
\hline \multirow[t]{2}{*}{$\begin{array}{c}12 \mathrm{~s} / \mathrm{d} \\
22\end{array}$} & $\begin{array}{c}\text { Ada } \\
\text { Halangan } \\
\end{array}$ & $\begin{array}{c}\text { Tidak } \\
\text { Mendeteksi }\end{array}$ \\
\hline & $\begin{array}{c}\text { Tanpa } \\
\text { Halangan }\end{array}$ & Mendeteksi \\
\hline$>23$ & $\begin{array}{c}\text { Ada dan } \\
\text { Tanpa } \\
\text { Halangan }\end{array}$ & $\begin{array}{c}\text { Tidak } \\
\text { Mendeteksi }\end{array}$ \\
\hline
\end{tabular}

Tabel 2. Hasil Pengujian Pengiriman Karakter

\begin{tabular}{|c|c|c|}
\hline $\begin{array}{c}\text { Karakter } \\
\text { Yang } \\
\text { Dikirim }\end{array}$ & $\begin{array}{c}\text { Putaran } \\
\text { Motor }\end{array}$ & Keterangan \\
\hline "1" & Maju & Berhasil \\
\hline "2" & Kiri & Berhasil \\
\hline "3" & Kanan & Berhasil \\
\hline "4" & Mundur & Berhasil \\
\hline
\end{tabular}

Tabel 3. Pengujian Tingkat Keakuratan Ultrasonik

\begin{tabular}{|c|c|}
\hline $\begin{array}{c}\text { Jarak } \\
\text { Terhadap } \\
\text { Objek }\end{array}$ & Keterangan \\
\hline $2 \mathrm{~cm}$ & Mendeteksi \\
\hline $50 \mathrm{~cm}$ & Mendeteksi \\
\hline $150 \mathrm{~cm}$ & Mendeteksi \\
\hline $300 \mathrm{~cm}$ & Mendeteksi \\
\hline $350 \mathrm{~cm}$ & Tidak Mendeteksi \\
\hline
\end{tabular}

Tabel 4. Hasil Pengujian Sensor Ultrasonik

\begin{tabular}{|c|c|c|c|}
\hline $\begin{array}{c}\text { Posisi } \\
\text { Sensor }\end{array}$ & Jarak & $\begin{array}{c}\text { Putaran } \\
\text { Motor }\end{array}$ & Ket \\
\hline Depan & $<15 \mathrm{~cm}$ & $\begin{array}{c}\text { Kiri } / \\
\text { Kanan }\end{array}$ & Ok \\
\hline Kiri & $<10 \mathrm{~cm}$ & Kanan & Ok \\
\hline Kanan & $<10 \mathrm{~cm}$ & Kiri & Ok \\
\hline Belakang & $<10 \mathrm{~cm}$ & Maju & Ok \\
\hline
\end{tabular}

\section{Kesimpulan}

Kesimpulan yang dapat diambil dari penyusunan penelitian ini adalah sebagai berikut :

1. Mobile robot mampu dikontrol oleh smartphone dengan mengunakan teknologi bluetooth

2. Mobile robot memiliki sistem yang otomatis dengan menggunakan sensor ultrasonik yang akan berbelok apabila terlalu dekat dengan objek yang ada disekitarnya untuk menghindari tabrakan.

3. Kecepatan mobile robot ini dapat diatur sesuai keinginan pengguna yaitu dengan memanfaatkan PWM (pulse width modulation) .

4. Jangkauan sensor ultrasonik dapat diatur sesuai dengan kondisi dinding (wall) yang dibuat sedemikian rupa.

\section{Saran}

Berdasarkan kesimpulan diatas dapat diberikan saran yang berkenaan dengan pengembangan dan penyempurnaan robot untuk penelitian selanjutnya:

1. Memberikan regulator khusus agar tegangan yang diberikan setiap komponen lebih stabil. 
2. Casing yang digunakan akan lebih baik apabila cukup besar, agar penempatan komponen yang efektif dan memiliki ruang yang cukup untuk pengkabelan.

\section{Daftar Pustaka}

[1] Sapto Aji Wahyu \& etc (2009, Desember).

"Purwarupa robot pemadam api dengan sensor ultrasonic dan ultraviolet berbasis AT89S52" Jurnal Program Studi Teknik Elektronika , Universitas Ahmad Dahlan, Yogyakarta.

[2] Tung, L. L. \& etc (2016, September). "Mobile robot yang dikontrol dengan teknologi bluetooth". Jurnal Teknik Elektronika Industri, Program studi Teknik Elektronika, Petra Christian University.

[3] Abdul Kadir (2013), Panduan Praktis Mempelajari Aplikasi Mikrokontroller dan Pemrogramannya menggunakan Arduino, Andi Yogyakarta .

[4] Abdul Kadir (2014), Buku Pintar Pemrograman Arduino, MediaKom

[5] Firmansyah Saftari (2015), Proyek Robotik Keren dengan Arduino, PT. Elex Media Komputindo

[6] Maurice Gaymar (2012), SRF-04 Ultrasonic Range Finder, Devantech Ltd Inggris.

[7] Jazi Eko Istiyanto (2014), Pengantar Elektronika dan Instrumentasi pendekatan procect Arduino dan Android, Andi Yogyakarta 